\title{
SENSITIVITY ANALYSIS IN THE HEAT TRANSFER IN A FINNED NUCLEAR FUEL ELEMENT
}

\author{
M. W. C. Tito ${ }^{\mathrm{a}}$, ABSTRACT \\ C. A. B. O. Lira ${ }^{a}$, \\ F. R. A. Lima ${ }^{b}$ \\ To carry out sensitivity analysis on a finned surface, the differential perturbative method \\ is applied in a heat conduction problem within a thermal system, made up of a one- \\ dimensional circumferential fin on a nuclear fuel element. The model is described by the \\ and J. L. Baliño ${ }^{c}$ \\ temperature distribution equation and the further specific boundary conditions. The adjoint \\ system is used to determine the sensitivity coefficients for the case of interest. Both, the \\ ${ }^{a}$ Universidade Federal de Pernambuco \\ Departamento de Energia Nuclear, \\ Av. Prof. Luiz Freire, 1000 \\ 50.740-540, Recife, PE, Brazil \\ cabol@ufpe.br \\ ${ }^{\mathrm{b}}$ Centro Regional de Ciências Nucleare \\ Rua Cônego Barata, 999 \\ Bairro da Tamarineira \\ 52.110-120, Recife, PE, Brazil. \\ 'Instituto de Pesquisas Energéticas \\ e Nucleares - Ipen/USP, \\ Cidade Universitária \\ 05508-900, São Paulo, SP, Brazil. \\ direct model and the resultant equations of the perturbative formalism are solved. The \\ convective heat flow rate of the fin and the average excess temperature were the response \\ functionals studied. The half thickness, the thermal conductivity and heat transfer \\ coefficients, and the excess temperature at the base of the fin were the parameters of \\ interest for the sensitivity analysis. The results obtained through the perturbative method \\ and the direct variation had, in a general form and within acceptable physical limits, good \\ concordance and excellent representativeness for the analyzed cases. It evidences that the \\ differential formalism is an important tool for the sensitivity analysis and also it validates \\ the application of the methodology in heat transmission problems on extended surfaces. \\ The method proves to be necessary and efficient while elaborating thermal engineering \\ projects \\ Keywords: perturbative methods, sensitivity analysis, heat transmission, extended surfaces, \\ fins.
}

\section{NOMENCLATURE}

$h \quad$ heat transfer coefficient, $\mathrm{W} /\left(\mathrm{m}^{2}{ }^{\circ} \mathrm{C}\right)$

$I$ modified Bessel function of the $1^{\text {st }}$ kind

$K \quad$ modified Bessel function of the $2^{\text {nd }}$ kind

$k$ thermal conductivity coefficient, $\mathrm{W} /\left(\mathrm{m} .{ }^{\circ} \mathrm{C}\right)$

$P \quad$ bilinear concomitant

$p$ parameter under analysis

$Q_{h}$ heat flow rate of the fin, $\mathrm{W}$

$q^{\prime \prime \prime} \quad$ volumetric power density, $\mathrm{W} / \mathrm{m}^{3}$

$R$ response functional of interest

$r$ radial coordinate, $\mathrm{m}$

$r_{0} \quad$ fuel element radius, $\mathrm{m}$

$r_{1}$ fin radius, $\mathrm{m}$

$r$ ' fin equivalent radius, $\mathrm{m}$

$S \quad$ absolute sensitivity coefficient

$S^{+} \quad$ source term of the adjoint equation

$S_{(i)}$ source term of the derivative equation

$t \quad$ fin temperature, ${ }^{\circ} \mathrm{C}$

$t_{f} \quad$ fluid temperature, ${ }^{\circ} \mathrm{C}$

$y_{0}$ half thickness of the fin, $\mathrm{m}$

\section{GREEK SYMBOLS}

$\dot{e} \quad$ excess temperature of the fin, ${ }^{\circ} \mathrm{C}$

$\dot{e}_{0} \quad$ excess temperature at the base of the fin, ${ }^{\circ} \mathrm{C}$ $\dot{e}^{*} \quad \begin{aligned} & \text { adjoint function for } \grave{e} \\ & \text { average value of } \grave{e}\end{aligned}$

\section{INTRODUCTION}

For thermal engineering, the complete analysis of the heat transmission is very important to assess appropriate dimensioning of the equipments, and to guarantee its efficiency, economy and security.

When there is a large difference in reference to the heat transfer coefficient, between two sides of a surface, the convective heat transport can be increased through the use of fins on the lower coefficient side, that is to say, extending the thermal contact area (Özişik, 1990).

The use of extended surfaces is currently very relevant because it makes possible the 


\section{CIÊNCIA/SCIENCE}

transmission of a large heat amount between fluids and surfaces. Those surfaces can be found in many thermal systems, such as: nuclear fuel elements, condensers and heat exchangers used at the industry, and also in vehicle radiators, air conditioners, microcomputers, gas turbines, cryogenics and other applications.

The use of fins on the nuclear fuel elements is a characteristic of gas-cooled nuclear reactors, because this fluid has a low heat transfer coefficient. There are few reactors that have this shape, only about 30 units around the world.

The fins on the fuel elements of those reactors have a peculiar role, because it is projected in a high heat density environment. Thus, it is a target of special cares, because the heat will need to be efficiently removed, including for security, becoming a very important system for advanced studies and future applications in many thermal equipments.

In the optimization of thermal systems is frequently used a computational model that represents the reality of the occurring phenomena. However, the entry data of the model, called parameters as well, are subject to many uncertainties or imprecisions that can impose important restrictions with regard to the reliability of the results in the output of the model (Tito, 2001).

Thus, the analysis of the system (thermal, for example), at the industrial sector or at scientific studies, will include the determination of the resultant influence of the variation, or perturbation, of some parameter of the problem in the behaviour of the system. This technique is known as sensitivity analysis (Lima, 1990).

The sensitivity analysis methodology, using the direct or conventional method, consists of the variation of one or more control parameters maintaining the other fixed. The calculation is repeated with the parameters of interest, constructing the called response surface (Albuquerque, 2001; Gurjão, 1996 and Tito, 2001). This method has several disadvantages, that makes it sometimes an impracticable methodology, because many parameters can cause alterations, or perturbations, in the system, and some models adopted for the calculations are very complex and time consuming (Lima and Blanco, 1994).

With reference to the perturbative methods, these are applied to the sensitivity analysis mainly
M. W. C. Tito et al. Sensitivity Analysis in the Heat...

when there is not an analytical solution for the model, and when its numerical solution is very onerous from a CPU-time standpoint (Tito, 2001). The principal advantage of these formalisms, in a general form, is the sensitivity calculation of the response with regard to the parameters without previous choosing of a given parameter and its variation range (the opposite of the direct method, where the previous choosing is compulsory). For the calculation of the new response, for each parameter variation, is used a simple resolution expression, and it works with a unique additional equation system for each analyzed response (Albuquerque, 2001). Thus, it makes viable the solution of the model in complex equations and it reduces the calculation time. The methodology is currently expanding to other engineering areas and industrial applications. Previous research works were successfully employed in these areas. Lira et. al. (1994) applies the formalism in a solute transfer model through soils; Gurjão et. al. (1996), in a U-tube steam generator model, used in light water cooled nuclear reactors; and Baliño et. al. (1995), in waterhammer problems in hydraulic networks.

The principal objective of this paper is to carry out a sensitivity analysis, using the differential formalism of the perturbation theory (Lima \& Blanco, 1994), to determine the influence of the parameter variations in the response functionals of interest. The method is applied to a problem of heat conduction, made up of a one-dimensional circumferential fin on a nuclear fuel element with specific boundary conditions. The convective heat flow rate of the fin and the average excess temperature were the response functionals studied. The half thickness, the thermal conductivity and heat transfer coefficients, and the excess temperature at the base of the fin were the parameters of interest for the sensitivity analysis. The obtained results will be discussed considering the influence of each studied parameter in the perturbation of the thermal system, for the given conditions. In this manner, the more sensible parameters will be determined, targets of a special care, while studying and elaborating projects of finned thermal equipments. The advantages and the validity of the application of heat transfer problems in extended surfaces will be presented. 


\section{CIÊNCIA/SCIENCE}

\section{THE MODEL OF THE CIRCUMFERENTIAL FIN OF UNIFORM THICKNESS}

\section{General considerations}

The circumferential fin of uniform thickness is a common kind of transversal extended surface, used in several thermal equipments, mainly in industrial heat exchanger pipes, as well as in gas-cooled nuclear reactor fuel elements.

The thermal sensitivity analysis, that is carried out through the application of the differential perturbative method, is the main focus of this paper. In this section, the model will be described with simplifying considerations and boundary conditions. Next, the temperature distribution equation of the fin is solved for the excess temperature in the fin.

\section{Description of the model, considerations and boundary conditions}

The model of the circumferential fin of uniform thickness, fixed on the nuclear fuel element, is shown on Fig. (1), where $r_{0}$ is the radius at the base of the fin (radius of the fuel element), $r_{1}$ is the radius of the fin and $2 y_{0}$ is the thickness of the fin (El-Wakil, 1971). The cylindrical coordinates and the Bessel functions for the solution of the problem are used to study the fin.

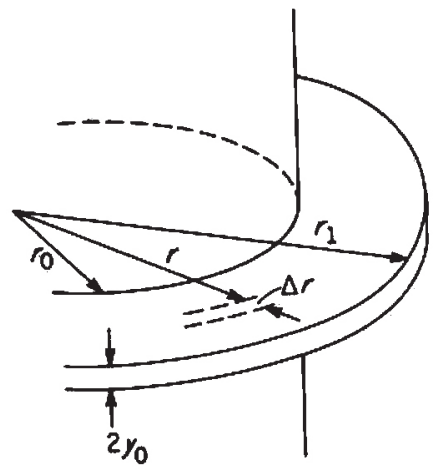

Figure 1. Circumferential fin of uniform thickness (El-Wakil, 1971).

Considerations for the studied model:

- the temperature of the coolant fluid, $t_{f}$, has a constant value around the fin;

- the heat transfer coefficient, $h$, has an uniform value along the fin;
M. W. C. Tito et al. Sensitivity Analysis in the Heat...

- the fin is made of a homogeneous material, and it is assumed that the thermal conductivity coefficient, $k$, has an uniform value;

- the temperature distribution and the heat conduction are one-dimensional for a low Biot number. The temperature is a function of the radius, $r$, only, because the thickness is very small if it is compared with the value of $r_{1}-r_{0}$;

- the heat generation within the fin is negligible, which is, $q^{\prime \prime \prime}=0$.

The temperature distribution of the fin is obtained through the analytical solution of the Eq. (1),

$$
\frac{d^{2} \theta}{d r^{2}}+\frac{1}{r} \frac{d \theta}{d r}-m_{0}^{2} \theta=0
$$

where $m_{0}^{2}=\frac{h}{k y_{0}}$ and $\theta$ is the excess temperature, which is, $t-t_{f}$ (where is the temperature of the fin).

The boundary conditions are obtained with the knowledge of the temperature and heat flux at two points of the fin:

$$
\begin{array}{lll}
\theta=\theta_{0} & \text { at } & r=r_{0} \\
\frac{d \theta}{d r}=0 & \text { at } & r=r_{1}+y_{0}=r^{\prime}
\end{array}
$$

The boundary condition given to is deduced through a process that the surface of the fin is extended, increasing its length at half of the original thickness, and the new tip is supposed to be insulated (El-Wakil, 1971). According to Kreith (1977), the errors in respect to that approximation are less than $8 \%$ for Biot numbers up to 0,5 . The studied case has a Biot number of 0,17 , using data from Tab. (1). Thus, is the equivalent radius of the fin.

The temperature distribution equation of the fin is given by:

$$
\theta=\theta_{0} \frac{K_{1}\left(m_{0} r^{\prime}\right) I_{0}\left(m_{0} r\right)+I_{1}\left(m_{0} r^{\prime}\right) K_{0}\left(m_{0} r\right)}{I_{0}\left(m_{0} r_{0}\right) K_{1}\left(m_{0} r^{\prime}\right)+I_{1}\left(m_{0} r^{\prime}\right) K_{0}\left(m_{0} r_{0}\right)}
$$

where $I$ and $K$ are the modified Bessel functions of the first and second kind, respectively. 


\section{CIÊNCIA/SCIENCE}

The physical and geometric properties of the fin are shown at Tab. (1).

Table 1. Data for the one-dimensional circumferential

\begin{tabular}{|l|c|}
\hline Fin material & $\begin{array}{c}\text { Stainless steel } \\
\text { type } 304\end{array}$ \\
\hline Thickness of the fin & $0.005 \mathrm{~m}$ \\
\hline Radius of the fuel element & $0.0125 \mathrm{~m}$ \\
\hline Radius of the fin & $0.0225 \mathrm{~m}$ \\
\hline Equivalent radius of the fin & $0.025 \mathrm{~m}$ \\
\hline Fluid temperature & $200{ }^{\circ} \mathrm{C}$ \\
\hline Temperature at the base of the fin & $350{ }^{\circ} \mathrm{C}$ \\
\hline Thermal conductivity coefficient & $18 \mathrm{~W} /\left(\mathrm{m}^{\circ} \mathrm{C}\right)$ \\
\hline Heat transfer coefficient & $600 \mathrm{~W} /\left(\mathrm{m}^{2}{ }^{\circ} \mathrm{C}\right)$ \\
\hline
\end{tabular}

Determination of the general Sensiti-vity coefficient - Application of the differential formalism

The sensitivity coefficient is the basic element of the sensitivity analysis using the perturbative methods. The differential formalism, developed by the perturbation theory, is one of the most direct and accurate tools among several proposed formulations. The system of adjoint equations is obtained by the following procedure (Gandini, 1987):

1 - derivation of the system of equations;

2 - extraction of the source terms $S_{(i)}$ of the derived system;

3 - obtainment of the adjoint operator;

4 - calculation of the bilinear concomitant;

5 - determination of the boundary conditions of the adjoint system.

The adjoint equation, the boundary conditions and the bilinear concomitant

Following the methodology indicated in Tito (2001) and Lima and Blanco (1994) for the differential formalism, it is found the adjoint system:

$$
\frac{d^{2}}{d r^{2}} \theta^{*}+\frac{1}{r} \frac{d}{d r} \theta^{*}-m_{0}^{2} \theta^{*}=S^{+}
$$

where $S^{+}$, the source term of the adjoint equation will be known when the response functionals are chosen.
M. W. C. Tito et al. Sensitivity Analysis in the Heat...

The boundary conditions of the adjoint equation were chosen to reduce the bilinear concomitant, producing a result that can be easily solved. Thus, the chosen boundary conditions are:

and

$$
\theta^{*}=0 \text { when } r=r_{0}
$$

$$
\frac{d}{d r} \theta *=0 \text { when } r=r^{\prime}
$$

The resultant bilinear concomitant is, then:

$$
P\left(\theta^{*}, \theta_{/ i}\right)=-2 \pi\left(r \frac{d}{d r} \theta^{*} \theta_{0 / i}\right)_{r_{0}}
$$

\section{Chosen cases for the sensitivity analysis}

a. Studied functionals

* Convective heat flow rate $-Q_{h}$

$$
Q_{h}=2 h \int_{r_{0}}^{r^{\prime}} \theta 2 \pi r d r
$$

where $S^{+}=2 h$ and the nominal value of the functional is obtained with from Eq. (2) and data from Tab. (1).

* Average excess temperature of the fin $-\bar{\theta}$

$$
\bar{\theta}=\frac{1}{\pi r^{\prime 2}-\pi r_{0}^{2}} \int_{r_{0}}^{r^{\prime}} \theta 2 \pi r d r
$$

where $S^{+}=\frac{1}{\pi r^{\prime 2}-\pi r_{0}^{2}}$ and the nominal value of the functional is obtained with from Eq. (2) and data from Tab. (1).

\section{b. Studied parameters}

The parameters for the sensitivity analysis were chosen with reference to its importance in the thermal engineering projects, given by:

* Half thickness of the fin $-y_{0}$

* Thermal conductivity coefficient $-k$

* Heat transfer coefficient - $h$

* Excess temperature at the base of the fin $-\theta_{0}$ 


\section{CIÊNCIA/SCIENCE}

\section{Calculation of the adjoint function $\theta^{*}$}

The value of is obtained through the solution of Eq. (3), since is a constant for both response functionals above, using the boundary conditions of the adjoint equation:

$$
\theta^{*}(r)=\frac{S^{+}}{m_{0}^{2}}\left[\frac{K_{1}\left(m_{0} r^{\prime}\right) I_{0}\left(m_{0} r\right)+I_{1}\left(m_{0} r^{\prime}\right) K_{0}\left(m_{0} r\right)}{I_{0}\left(m_{0} r_{0}\right) K_{1}\left(m_{0} r^{\prime}\right)+I_{1}\left(m_{0} r^{\prime}\right) K_{0}\left(m_{0} r_{0}\right)}-1\right]
$$

A graphic analysis of the functional, for a radius variation, is used to observe the behaviour of the adjoint function in the differential formalism of the perturbative method. Thus, it is possible a study of the importance function (Gandini, 1987) along the fin, which is, the perturbation contributions in the response functional, whose graph is shown in Fig. (2).

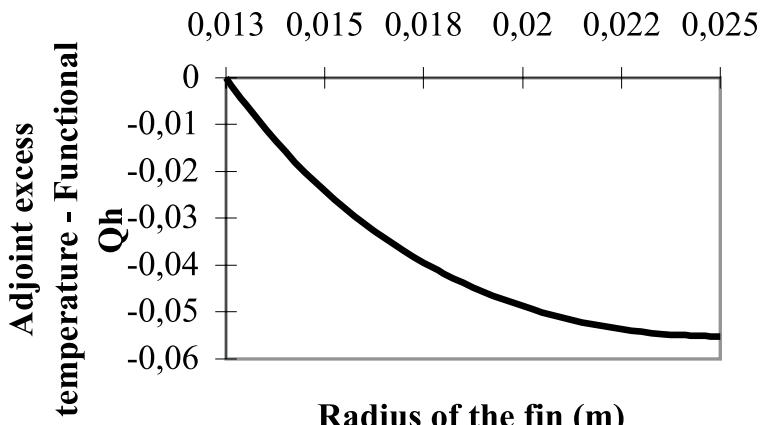

Figure 2. Adjoint excess temperature versus radius of the fin - Functional

\section{Sensitivity coefficients} analysis is:

The general expression for the sensitivity

$$
\frac{\delta R}{\delta p_{i}}=<\theta S_{/ i}^{+}>+<\theta^{*} S_{(i)}>+P\left(\theta^{*}, \theta_{l i}\right)
$$

Table 2. Expressions for the sensitivity coefficients.

\begin{tabular}{|l|c|c|}
\hline & \multicolumn{2}{|c|}{ Functionals } \\
\hline Parameters & $Q_{h}(W)$ & $\bar{\theta}\left({ }^{\circ} C\right)$ \\
\hline$y_{0}$ & $-\frac{m_{o}^{2}}{y_{o}}<\theta \theta^{*}>$ & $-\frac{m_{o}^{2}}{y_{o}}<\theta \theta^{*}>$ \\
\hline $\mathbf{k}$ & $-\frac{m_{o}^{2}}{k}<\theta \theta^{*}>$ & $-\frac{m_{o}^{2}}{k}<\theta \theta^{*}>$ \\
\hline $\mathrm{h}$ & $2<\theta>+\frac{m_{o}^{2}}{h}<\theta \theta^{*}>$ & $\frac{m_{o}^{2}}{h}<\theta \theta^{*}>$ \\
\hline$\theta_{0}$ & $-2 \pi r_{o}\left[\frac{d \theta^{*}}{d r}\right]_{r=r_{o}}$ & $-2 \pi r_{o}\left[\frac{d \theta^{*}}{d r}\right]_{r=r_{o}}$ \\
\hline
\end{tabular}

M. W. C. Tito et al. Sensitivity Analysis in the Heat...

where $\left\langle f>\right.$ means $\int_{r_{0}}^{r^{\prime}} f 2 \pi r d r$. Table 2 shows particular expressions for each functionalparameter combination.

\section{RESULTS ANALYSIS}

Table (3) gives the sensitivity coefficients, calculated using data from Tab. (1) and a numerical computational program.

Table 3. Sensitivity coefficients.

\begin{tabular}{|c|c|c|}
\hline & \multicolumn{2}{|c|}{ Functionals } \\
\hline Parameters & $Q_{h}(\mathrm{~W})$ & $\bar{\theta}\left({ }^{\circ} \mathrm{C}\right)$ \\
\hline$y_{0}$ & $23.630 \mathrm{~W} / \mathrm{m}$ & $13.370{ }^{\circ} \mathrm{C} / \mathrm{m}$ \\
\hline$k$ & $3.282 \mathrm{~m}^{\circ} \mathrm{C}$ & $1.857 \mathrm{~m}^{\circ} \mathrm{C}^{2} / \mathrm{W}$ \\
\hline$h$ & $0.137 \mathrm{~m}^{2}{ }^{\circ} \mathrm{C}$ & $-0.056 \mathrm{~m}^{2}{ }^{\circ} \mathrm{C}^{2} / \mathrm{W}$ \\
\hline$\theta_{0}$ & $0.941 \mathrm{~W} /{ }^{\circ} \mathrm{C}$ & 0.533 \\
\hline
\end{tabular}

Table (3) shows relative values, where it is not possible to make a comparison about the parametric influence in an absolute way. So, to make possible a comparison, the sensitivity $S$ (or absolute sensitivity coefficient) is defined as:

$$
S=\frac{\delta R}{\delta p} \frac{p_{0}}{R_{0}}
$$

where $\frac{\delta R}{\delta p}$ is the relative sensitivity coefficient and and $p_{0}$ are the nominal values at the reference point.

First of all, the nominal values of the parameters and functionals are presented below in Tab. (4); next, the absolute sensitivity coefficients.

Table 4. Values of functionals without perturbation (nominal values).

\begin{tabular}{|l|c|}
\hline \multicolumn{2}{|c|}{ Functionals } \\
\hline$Q_{h}(W)$ & 141,198 \\
\hline $\bar{\theta}\left({ }^{\circ} C\right)$ & 79,902 \\
\hline
\end{tabular}

Table (5) shows the absolute sensitivity coefficients for the comparative effects with reference to the influence of the parameters in the response functional of interest. 


\section{CIÊNCIA/SCIENCE}

Table 5. Absolute sensitivity coefficients.

\begin{tabular}{|c|c|c|}
\hline & \multicolumn{2}{|c|}{ Functionals } \\
\hline Parameters & $Q_{h}(W)$ & $\bar{\theta}\left({ }^{\circ} C\right)$ \\
\hline$y_{0}$ & 0,4183 & 0,4183 \\
\hline$k$ & 0,4183 & 0,4183 \\
\hline$h$ & 0,5820 & $-0,4205$ \\
\hline$\theta_{0}$ & 0,9997 & 1,0006 \\
\hline
\end{tabular}

As a first analysis of the table, $\theta_{0}$ is the parameter that causes the greater influence in the response functional $\bar{\theta}$. In other words, for each $1 \%$ uncertainty in the parameter, the functional has almost the same percentage of variation. The other parameters cause practically the same influence in the functionals, observing that $h$ has an opposite influence in .

Table (6) shows the obtained results through the use of the direct method, Eqs. (5) and (6), and the differential perturbative method (data from Tab. (3) and Tab. (4)), with the relative errors in percentage. Its objective is to verify the precision of the utilized formalism. The values were calculated using the data available in Tab. (1).

At Tab. (6), the differential formalism presents the following results:

- The relative errors are below $1 \%$ and most of them below $0,5 \%$. Thus, the used method has a good precision. With regard to the parameter, there is a very high accuracy, as expected;

- The description is correct in respect to the variation tendency of the functionals. It proves its good representativeness. As for an example, the functionals show a correct tendency to parameter variations if compared to the reference value.

\section{CONCLUSIONS}

Through the obtained results, the first conclusion is that the absolute sensitivity coefficient is essential for the determination of the more sensible parameters in a response functional. The method presented a good representativeness for the analyzed cases, where most of the cases had a good precision and accuracy.

The most influential parameters at the response functional were (heat transfer coefficient) and (excess temperature at the base of the fin). About the functional, was the most influential as well.
M. W. C. Tito et al. Sensitivity Analysis in the Heat...

Another observed advantage is that the repetitions to obtain the perturbated values are eliminated through the determination of the sensitivity coefficient.

The good results, obtained with the use of the formalism at the model, demonstrated the validity of the application for heat transmission problems on extended surfaces, where it becomes a very important technique to elaborate thermal engineering projects.

Table 6. Direct method versus differential perturbative method.

\begin{tabular}{|c|c|c|c|c|c|c|c|c|}
\hline & & Functionals & & $Q_{h}(W)$ & & & $\bar{\theta}\left({ }^{\circ} \mathrm{C}\right)$ & \\
\hline & & $\delta p / p_{0}(x 100)^{a}$ & $\mathrm{DM}^{b}$ & $\mathrm{PM}^{c}$ & Error \% & $\mathrm{DM}^{b}$ & $\mathrm{PM}^{c}$ & Error \% \\
\hline & & $-15 \%$ & 131.642 & 132.336 & 0.527 & 74.494 & 74.888 & 0.529 \\
\hline & & $-10 \%$ & 134.989 & 135.290 & 0.223 & 76.388 & 76.559 & 0.224 \\
\hline & & $-5 \%$ & 138.171 & 138.244 & 0.053 & 78.189 & 78.230 & 0.052 \\
\hline & $y_{0}$ & $0 \%$ & 141.198 & 141.198 & 0.000 & 79.902 & 79.902 & 0.000 \\
\hline & $(m)$ & $5 \%$ & 144.082 & 144.151 & 0.048 & 81.534 & 81.573 & 0.048 \\
\hline & & $10 \%$ & 146.834 & 147.105 & 0.185 & 83.091 & 83.244 & 0.184 \\
\hline & & $15 \%$ & 149.642 & 150.059 & 0.279 & 84.578 & 84.915 & 0.398 \\
\hline & & $-15 \%$ & 131.642 & 132.336 & 0.161 & 74.494 & 74.888 & 0.529 \\
\hline & & $-10 \%$ & 134.989 & 135.290 & 0.113 & 76.388 & 76.559 & 0.224 \\
\hline & & $-5 \%$ & 138.171 & 138.244 & 0.050 & 78.189 & 78.230 & 0.052 \\
\hline & $k$ & $0 \%$ & 141.198 & 141.198 & 0.000 & 79.902 & 79.902 & 0.000 \\
\hline & $\left(\mathrm{W} / \mathrm{m}^{\circ} \mathrm{C}\right)$ & $5 \%$ & 144.082 & 144.151 & 0.048 & 81.534 & 81.573 & 0.048 \\
\hline & & $10 \%$ & 146.834 & 147.105 & 0.185 & 83.091 & 83.244 & 0.184 \\
\hline \multirow[t]{15}{*}{$p_{i}$} & & $15 \%$ & 149.642 & 150.059 & 0.279 & 84.578 & 84.915 & 0.398 \\
\hline & & $-15 \%$ & 128.185 & 128.868 & 0.533 & 85.339 & 84.942 & 0.465 \\
\hline & & $-10 \%$ & 132.686 & 132.978 & 0.220 & 83.427 & 83.262 & 0.198 \\
\hline & & $-5 \%$ & 137.019 & 137.088 & 0.050 & 81.618 & 81.582 & 0.044 \\
\hline & $h$ & $0 \%$ & 141.198 & 141.198 & 0.000 & 79.902 & 79.902 & 0.000 \\
\hline & $\left(\mathrm{W} / \mathrm{m}^{2}{ }^{\circ} \mathrm{C}\right)$ & $5 \%$ & 145.234 & 145.308 & 0.050 & 78.272 & 78.222 & 0.064 \\
\hline & & $10 \%$ & 149.138 & 149.418 & 0.187 & 76.722 & 76.542 & 0.235 \\
\hline & & $15 \%$ & 152.918 & 153.528 & 0.399 & 75.247 & 74.682 & 0.751 \\
\hline & & $-15 \%$ & 120.018 & 120.025 & 0.006 & 67.916 & 67.909 & 0.010 \\
\hline & & $-10 \%$ & 127.078 & 127.083 & 0.004 & 71.911 & 71.907 & 0.006 \\
\hline & & $-5 \%$ & 134.138 & 134.140 & 0.001 & 75.907 & 75.905 & 0.003 \\
\hline & $\theta_{0}$ & $0 \%$ & 141.198 & 141.198 & 0.000 & 79.902 & 79.902 & 0.000 \\
\hline & $\left({ }^{\circ} \mathrm{C}\right)$ & $5 \%$ & 148.258 & 148.255 & 0.002 & 83.897 & 83.899 & 0.002 \\
\hline & & $10 \%$ & 155.318 & 155.313 & 0.003 & 87.892 & 87.897 & 0.006 \\
\hline & & $15 \%$ & 162.377 & 162.370 & 0.004 & 91.887 & 91.894 & 0.008 \\
\hline
\end{tabular}

a. Relative variation of the parameter (percentage).

b. Direct method (standard value).

c. Differential perturbative method.

\section{REFERENCES}

Albuquerque, C. D., Manzi, J. T., Brayner, C. A. and Odloak, D., 2000, Stability Conditions and Sensitivity Analysis for the Neutralization Process with a Nonlinear PI Controller, in: $19^{\text {th }}$ IASTED International Conference - Modelling, Identification and Control, Innsbruck, Austria, pp. 207-211. 
Baliño, J. L., Larreteguy, A., Lorenzo, A. and Lima, F. R. A., 1995, Application of Perturbation Methods and Sensitivity Analysis to Waterhammer Problems in Hydraulic Networks, in: $10^{\text {th }}$ Brazilian Meeting on Reactor Physics and Thermal-Hydraulics, Águas de Lindóia - MG, Brazil, pp. 184-189.

El-Wakil, M. M., 1971, Nuclear Heat Transport, Intext Educational Publishers, New York, USA.

Gandini, A., 1987, Generalized Perturbation Theory (GPT) Methods. A Heuristic Approach, Advances in Nuclear and Science Technology, Vol.19, pp. 205-380.

Gurjão, E. C., Lira, C. A. B. O. and Lima, F. R. A., 1996, Aplicação da Teoria da Perturbação à Análise de Sensibilidade em Geradores de Vapor de Usinas Nucleares, in: VI Congresso Geral de Energia Nuclear, Rio de Janeiro - RJ, Brazil.

Kreith, F., 1977, Princípios de Transmissão de Calor, Editora Edgard Bluecher Ltda., São Paulo, Brazil.

Lima, F. R. A., 1990, Aplicações de Métodos Perturbativos ao Modelo Multicanal COBRA-IV-I, para Cálculos de Sensibilidade em Núcleos de Reatores Nucleares, Tese - Programa de Engenharia Nuclear/COPPE, Universidade Federal do Rio de Janeiro, Rio de Janeiro - RJ, Brazil, 425 p.

Lima, F. R. A. and Blanco, A., 1994, Introduccion a los Metodos Perturbativos Aplicados a Problemas de Ingenieria Nuclear, CNEA, Universidad Nacional de Cuyo, Instituto Balseiro, San Carlos de Bariloche, Argentina, 61 p.

Lira, C. A. B. O., Antonino, A. C. D., Lima F. R. A. and Carneiro, C. J. G., 1994, Análise de Sensibilidade de um Modelo de Transferência de Soluto em Solos Através de Métodos Perturbativos, in: III Congresso de Engenharia Mecânica do Norte-Nordeste, Belém - PA, Brazil, pp. 94-97.

Özişik, M. N., 1990, Transferência de Calor, Editora Guanabara Koogan S.A., Rio de Janeiro - RJ, Brazil.

Tito, M. W. C., 2001, Análise de Sensibilidade na Difusão de Calor em uma Aleta de um Elemento Combustível Nuclear, Dissertação - Departamento de Energia Nuclear, Universidade Federal de Pernambuco, Recife-PE, Brazil, 103p. 